\title{
Mechanism for resveratrol-induced cardioprotection against reperfusion injury involves glycogen synthase kinase $3 \beta$ and mitochondrial permeability transition pore
}

\author{
Jinkun Xia,b,c, Huihua Wang ${ }^{\mathrm{a}}$, Robert A. Muellera ${ }^{\mathrm{a}}$ Edward A. Norfleet ${ }^{\mathrm{a}}$, and Zhelong Xu ${ }^{\mathrm{a}}{ }^{\text {* }}$ \\ a Department of Anesthesiology, University of North Carolina at Chapel Hill, NC 27599, United \\ States \\ b Department of Physiology, Yanbian University, Yanji, China \\ ${ }^{c}$ Heart Institute, North China Coal Medical University, Tangshan, China
}

\begin{abstract}
Resveratrol pretreatment can protect the heart by inducing pharmacological preconditioning. Whether resveratrol protects the heart when applied at reperfusion remains unknown. We examined the effect of resveratrol on myocardial infarct size when given at reperfusion and investigated the mechanism underlying the effect. Isolated rat hearts were subjected to $30 \mathrm{~min}$ ischemia followed by $2 \mathrm{~h}$ of reperfusion, and myocardial samples were collected from the risk zone for Western blot analysis. Mitochondrial swelling was spectrophotometrically measured as a decrease in absorbance at $520 \mathrm{~nm}\left(A_{520}\right)$. Resveratrol reduced infarct size and prevented cardiac mitochondrial swelling. Resveratrol enhanced GSK-3 $\beta$ phosphorylation upon reperfusion, an effect that was mediated by the cyclic guanosine monophosphate (cGMP)/protein kinase G(PKG) pathway. Resveratrol translocated GSK-3 $\beta$ from cytosol to mitochondria via the cGMP/PKG pathway. Further studies showed that mitochondrial GSK-3 $\beta$ was co-immunoprecipitated with cyclophilin D but not with VDAC (voltage dependent anion channel) or ANT (adenine nucleotide translocator). These data suggest that resveratrol prevents myocardial reperfusion injury presumably by targeting the mPTP through translocation of GSK-3 $\beta$ from cytosol to mitochondria. Translocated GSK-3 $\beta$ may ultimately interact with cyclophilin D to modulate the mPTP opening.
\end{abstract}

\section{Keywords}

Resveratrol; Reperfusion injury; Glycogen synthase kinase 3ß; Mitochondrial permeability transition pore

\footnotetext{
(C) 2008 Elsevier B.V. All rights reserved.

* Corresponding author. Department of Anesthesiology, CB\# 7010, University of North Carolina at Chapel Hill, Chapel Hill, NC 27599, United States. Tel.: +1 919843 4174; fax: +1 919843 3805. zxu@ @aims.unc.edu (Z. Xu).

Publisher's Disclaimer: This article appeared in a journal published by Elsevier. The attached copy is furnished to the author for internal non-commercial research and education use, including for instruction at the authors institution and sharing with colleagues. Other uses, including reproduction and distribution, or selling or licensing copies, or posting to personal, institutional or third party websites are prohibited. In most cases authors are permitted to post their version of the article (e.g. in Word or Tex form) to their personal website or institutional repository. Authors requiring further information regarding Elsevier's archiving and manuscript policies are encouraged to visit: http://www.elsevier.com/copyright
} 


\section{Introduction}

First isolated from the roots of white hellebore in 1940, resveratrol (3,5,4'-trihydroxystilbene) is a polyphenolic product found abundantly in grapes and red wines. Studies have shown that resveratrol exerts numerous biological effects including antioxidant (Frankel et al., 1993), anticancer (Jang et al., 1997), anti-ageing (Wood et al., 2004), and anti-inflammation (Birrell et al., 2005). Recent studies have demonstrated that resveratrol can protect the heart from ischemia/reperfusion injury by eliciting pharmacological preconditioning (Bradamante et al., 2003; Das et al., 2005a; Hattori et al., 2002). Nitric oxide (NO) (Hattori et al., 2002; Hung et al., 2004; Imamura et al., 2002), adenosine receptors (Das et al., 2005a,b), PI3 kinase (Das et al., 2006a,b), and mitogen-activated protein kinase (MAPK) (Das et al., 2006a,b) have been proposed to mediate the cardioprotective effect of resveratrol-induced pharmacological preconditioning. While preconditioning can effectively protect the heart from ischemia/ reperfusion injury, it can hardly be applied in the clinical setting of acute myocardial infarction because of the requirement for pretreatment. In addition, restoration of blood flow after ischemia also causes myocardial damage, so called reperfusion injury (Braunwald and Kloner, 1985). Thus, it is important to determine if resveratrol applied at reperfusion can also protect the heart from ischemia/reperfusion injury.

If resveratrol is protective when given at reperfusion, it is interesting to define the potential cellular and molecular mechanisms underlying the protection. The mitochondrial permeability transition pore (mPTP) opening has been proposed to play an important role in myocardial ischemia/reperfusion injury (Suleiman et al., 2001; Weiss et al., 2003). The mPTP remains closed during ischemia but opens at the onset of reperfusion (Griffiths and Halestrap, 1995), and modulation of the mPTP opening at early reperfusion can protect the heart from reperfusion injury (Argaud et al., 2005a,b; Halestrap et al., 2004; Hausenloy et al., 2003, 2002). Since resveratrol protects the heart through a NO-dependent mechanism (Hattori et al., 2002; Hung et al., 2004) and NO has been demonstrated to prevent the mPTP opening (Wang et al., 2005), it is possible that resveratrol could modulate the mPTP opening at reperfusion.

Identified as a regulator of glycogen metabolism, glycogen synthase kinase $3 \beta$ (GSK-3 $\beta$ ) is now a well established component contributing to cell signaling, protein synthesis, cell proliferation, cell differentiation, cell adhesion, and apoptosis (Frame and Cohen, 2001). Studies have shown that GSK-3 $\beta$ plays a role in ischemic preconditioning (Tong et al., 2002) and in morphine-induced cardioprotection at reperfusion (Gross et al., 2004). In addition, a recent study has shown that GSK- $3 \beta$ plays a central role in pharmacological preconditioning induced modulation of the mPTP opening (Juhaszova et al., 2004). Importantly, we have recently demonstrated that bradykinin (Park et al., 2006b) and IB-MECA (Park et al., 2006a) given at reperfusion protect the heart by targeting the mPTP through inhibition of GSK-3 $\beta$. Furthermore, resveratrol can activate the PI3K/Akt (Das et al., 2006a) and mitogen-activated protein kinase (Das et al., 2006b) and these signaling kinases have been demonstrated to negatively regulate GSK-3 $\beta$. Therefore, it isintriguing to determine whether GSK- $3 \beta$ is involved in the action of resveratrol, if resveratrol protects the heart at reperfusion by targeting the mPTP.

In this study, we first examined if resveratrol applied at reperfusion could reduce infarct size in rat hearts. Then, we determined whether resveratrol protects the heart by targeting the $\mathrm{mPTP}$ through inhibition of GSK-3 $\beta$. Lastly, we investigated the mechanism by which GSK-3 $\beta$ inhibition leads to inhibition of the mPTP opening. 


\section{Materials and methods}

This study conforms to the NIH Guide for the Care and Use of Laboratory Animals (NIH publication NO. 85-23, revised 1996).

\subsection{Chemicals and antibodies}

Resveratrol was purchased from Sigma Chemical (St. Louis, MO) and ODQ was obtained from EMD Biosciences, Inc. (La Jolla, CA). All antibodies were purchased from Cell Signaling Technology Inc. (Beverly, MA).

\subsection{Perfusion of isolated rat hearts}

Male Wistar rats (250-350 g) were anesthetized with thiobutabarbital sodium ( $100 \mathrm{mg} / \mathrm{kg}$ i.p.). The hearts were removed rapidly and mounted on a Langendorff apparatus. The hearts were perfused with Krebs-Henseleit buffer containing (in $\mathrm{mM}$ ) $118.5 \mathrm{NaCl}, 4.7 \mathrm{KCl}, 1.2 \mathrm{MgSO}_{4}$, $1.8 \mathrm{CaCl}_{2}, 24.8 \mathrm{NaHCO}_{3}, 1.2 \mathrm{KH}_{2} \mathrm{PO}_{4}$, and 10 glucose, which was heated to $37{ }^{\circ} \mathrm{C}$ and gassed with $95 \% \mathrm{O}_{2} / 5 \% \mathrm{CO}_{2}$. A latex balloon connected to a pressure transducer was inserted into the left ventricle through the left atrium. The left ventricular pressure and heart rate were continuously recorded with a PowerLab system (ADInstruments, Mountain View, CA). A 5-0 silk suture was placed around the left coronary artery, and the ends of the suture were passed through a small piece of soft vinyl tubing to form a snare. All hearts were allowed to stabilize for at least $20 \mathrm{~min}$. Ischemia was induced by pulling the snare and then fixing it by clamping the tubing with a small hemostat. Total coronary artery flow was measured by timed collection of the perfusate dripping from the heart into a graduated cylinder.

\subsection{Measurement of infarct size}

At the end of the experiments, the coronary artery was re-occluded, and fluorescent polymer microspheres (2-9 $\mu \mathrm{M}$ diameter, Duke Scientific Corp) were infused to demarcate the risk zone as the tissue without fluorescence. The hearts were weighed, frozen and cut into $1 \mathrm{~mm}$ slices. The slices were incubated in $1 \%$ triphenyltetrazolium chloride (TTC) in sodium phosphate buffer at $37^{\circ} \mathrm{C}$ for $20 \mathrm{~min}$. The slices were immersed in $10 \%$ formalin to enhance the contrast between stained (viable) and unstained (necrotic) tissue and then squeezed between glass plates spaced exactly $1 \mathrm{~mm}$ apart. The myocardium at risk was identified by illuminating the slices with U.V. light. The infarcted and risk zone regions were traced on a clear acetate sheet and quantified with ImageTool. The areas were converted into volumes by multiplying the areas by slice thickness. Infarct size is expressed as a percentage of the risk zone.

\subsection{Isolation of adult rat cardiomyocytes}

Rat cardiomyocytes were isolated enzymatically (Xu et al., 2005). Male Wistar rats weighing $250-350 \mathrm{~g}$ were anesthetized with thiobutabarbital sodium $(100 \mathrm{mg} / \mathrm{kg}$, i.p.). A midline thoracotomy was performed and the heart was removed and rapidly mounted on a Langendorff apparatus. The heart was perfused in a non-recirculating mode with Krebs-Henseleit buffer $\left(37^{\circ} \mathrm{C}\right.$ ) containing (in mM) NaCl 118, $\mathrm{NaHCO}_{3} 25, \mathrm{KCl} 4.7, \mathrm{KH}_{2} \mathrm{PO}_{4} 1.2, \mathrm{MgSO}_{4} 1.2$, $\mathrm{CaCl}_{2}$ 1.25, and glucose 10 for 5 min to wash out blood. The buffer was bubbled with $95 \%$ $\mathrm{O}_{2} / 5 \% \mathrm{CO}_{2}$. Then the heart was perfused with a calcium-free buffer that contained all of the above components except $\mathrm{CaCl}_{2}$. After 5 min of perfusion, collagenase (type II) was added to the buffer $(0.1 \%)$ and the heart was perfused in a recirculating mode for $\sim 15 \mathrm{~min}$. The heart was removed from the apparatus and the ventricles were placed into a beaker containing the calcium-free buffer. The ventricles were agitated in a shaking bath $\left(37^{\circ} \mathrm{C}\right)$ at a rate of $50 \mathrm{cycles} /$ min until individual cells were released. The released cells were suspended in an incubation buffer containing all the components of the calcium-free buffer, $1 \%$ bovine serum albumin, 30 $\mathrm{mM}$ HEPES, $60 \mathrm{mM}$ taurine, $20 \mathrm{mM}$ creatine, and amino acid supplements at $37^{\circ} \mathrm{C}$. Calcium 
was gradually added to the buffer containing the cells to a final concentration of $1.2 \mathrm{mM}$. The cells were filtered through nylon mesh and centrifuged briefly. Finally the cells were suspended in culture medium M199 for $4 \mathrm{~h}$ before experiments.

\subsection{Mitochondrial isolation}

Mitochondria and cytosolic fractions were isolated by differential centrifugation as previously described (Baines et al., 2002). Cardiac samples (or isolated cardiomyocytes) were homogenized in a buffer containing $250 \mathrm{mM}$ sucrose, $10 \mathrm{mM}$ Tris- $\mathrm{HCl}$ (pH 7.4), $1 \mathrm{mM} \mathrm{EDTA \text {, }}$ $1 \mathrm{mM} \mathrm{Na}_{3} \mathrm{VO}_{4}, 1 \mathrm{mM} \mathrm{NaF}$, and protease inhibitor cocktail. The homogenate was centrifuged at $1000 \mathrm{~g}$ for $10 \mathrm{~min}$ to remove nuclei and debris. The supernatant was centrifuged at 10,000 $\mathrm{g}$ for $30 \mathrm{~min}$. The resultant supernatant was subsequently centrifuged at $10,000 \mathrm{~g}$ for $1 \mathrm{~h}$ to yield the cytosolic fraction. The $10,000 \mathrm{~g}$ pellet, corresponding to the mitochondrial fraction, was resuspended and centrifuged again at $10,000 \mathrm{~g}$ for $30 \mathrm{~min}$. Mitochondria were then resuspended in swelling buffer (for swelling experiments) and homogenized (for Western and immunoprecipitation).

\subsection{Measurement of mitochondrial swelling}

Intact mitochondria $(0.3 \mathrm{mg} / \mathrm{ml})$ isolated from cardiac samples taken $10 \mathrm{~min}$ after the onset of reperfusion were suspended in a buffer containing (in $\mathrm{mM}$ ) $120 \mathrm{KCl}, 10$ Tris-HCl, 5 $\mathrm{KH}_{2} \mathrm{PO}_{4}$, and 20 MOPS. Mitochondrial swelling was assessed spectrophotometrically as a decrease in absorbance at $520 \mathrm{~nm}\left(\mathrm{~A}_{520}\right)$ (Wang et al., 2005).

\subsection{Western blotting analysis}

Myocardial samples taken from risk zones were homogenized in ice-cold lysis buffer. Equal amounts of protein were loaded and electrophoresed on SDS-polyacrylamide gel and transferred to a PVDF membrane. Membranes were blocked with nonfat milk, and then incubated with the primary antibodies $(1: 1000)$ at $4{ }^{\circ} \mathrm{C}$ overnight. The primary antibody bindings were detected with a secondary anti-rabbit antibody (1:2000) and visualized by the ECL method. Equal loading of samples was confirmed by reprobing membranes with antibodies that recognize total proteins (phospho- and nonphospho-). Protein bands were quantitated with a densitometer (UVP, Upland, CA) and individual enzyme activities were expressed as \% changes of densities relative to "controls".

\subsection{Immunoprecipitation}

Mitochondrial samples were incubated with anti-GSK-3 $\beta$, anti-VDAC, anti-ANT, and anticyclophilin D plus Protein A/G agarose overnight at $4{ }^{\circ} \mathrm{C}$. After washing five times with lysis buffer, the pellet was subjected to SDS-PAGE and immunoblotting.

\subsection{Experimental protocols}

In "control" group, hearts were subjected to a 30 min regional ischemia followed by $2 \mathrm{~h}$ of reperfusion. In "resveratrol" group, hearts ( $30 \mathrm{~min}$ ischemia and $2 \mathrm{~h}$ reperfusion) were treated with resveratrol $(10 \mu \mathrm{M})$ and inhibitors starting 5 min before the onset of reperfusion for 35 min. Biopsies were collected from risk zones at 5 and 10 min after the onset of reperfusion. Infarct size was measured $2 \mathrm{~h}$ after reperfusion. For the immunoprecipitation study, isolated rat cardiomyocytes were exposed to resveratrol for $10 \mathrm{~min}$.

\subsection{Statistical analysis}

Data are expressed as mean \pm S.E.M. and were obtained from 5 to 10 separate experiments. Statistical significance was determined using Student $t$-test or one-way ANOVA followed by Tukey's test. A value of $P<0.05$ was considered as statistically significant. 


\section{Results}

\subsection{Effects of resveratrol on myocardial infarct size and the mPTP opening}

To determine if resveratrol given at reperfusion can protect the heart from ischemia/reperfusion injury, we measured myocardial infarct size in isolated perfused rat hearts. There were no significant differences in baseline hemodynamic indexes, heart weight, body weight, and the risk zone among experimental groups. In previous studies, Das et al. have demonstrated that the cardioprotective effect of resveratrol was noticed at $10 \mu \mathrm{M}$ in isolated rat hearts (Das et al., $2005 \mathrm{~b}, 2006 \mathrm{~b}$ ). In this study, we performed all experiments with $10 \mu \mathrm{M}$ resveratrol. As shown in Fig. 1A, resveratrol $(10 \mu \mathrm{M})$ applied starting 5 min prior to the onset of reperfusion for 30 min markedly reduced infarct size compared with the control hearts, suggesting that resveratrol is capable of protecting the heart by inhibiting reperfusion injury. Resveratrol also improved cardiac contractile function during reperfusion, as indicated by a significant increase in left ventricular developed pressure (LVDP) at $2 \mathrm{~h}$ of reperfusion (Fig. 1B). Since the mitochondrial permeability transition pore (mPTP) opening plays a critical role in the pathogenesis of reperfusion injury, it is possible that resveratrol prevents reperfusion injury by inhibiting the pore opening. Therefore, we then determined if resveratrol could prevent the MPTP opening by detecting changes in light absorbance (Hadzimichalis et al., 2007). As shown in Fig. 1C, mitochondria isolated from the hearts treated with resveratrol revealed a greater value in $A_{520}$ compared with control, indicating that resveratrol does inhibit the mPTP opening upon reperfusion.

\subsection{Effect of resveratrol on GSK-3 $\beta$ activity at reperfusion}

Since GSK-3 $\beta$ inactivation leads to inhibition of the mPTP opening (Juhaszova et al., 2004), we determined the effect of resveratrol on GSK-3 $\beta$ activity by detecting its phosphorylation at $\operatorname{Ser}^{9}$ upon reperfusion in isolated rat hearts. Since the mPTP opens in the first few minutes of reperfusion but not during ischemia (Griffiths and Halestrap, 1995), GSK-3 $\beta$ activity should be regulated by resveratrol early during reperfusion, if resveratrol prevents the mPTP opening through GSK-3 $\beta$. Thus, we detected GSK-3 $\beta$ phosphorylation 5 and 10 min after the onset of reperfusion. As shown in Fig. 2, resveratrol given starting 5 min before reperfusion significantly enhanced GSK-3 $\beta$ phosphorylation at 5 and 10 min of reperfusion, implying that GSK-3 $\beta$ may serve as a critical signal that mediates the effect of resveratrol on the mPTP opening. We then tested if the cyclic guanosine monophosphate (cGMP)/protein kinase $G$ (PKG) pathway accounts for the action of resveratrol, because NO has been proposed to play a role in the cardioprotective effect of resveratrol (Hattori et al., 2002). Fig. 3 shows that the effect of resveratrol on GSK-3 $\beta$ activity was reversed by ODQ $(5 \mu \mathrm{M})$, a potent and selective inhibitor of NO-sensitive guanylyl cyclase, implying that cGMP is responsible for the action of resveratrol. Further experiments showed that resveratrol markedly increased phosphorylation of vasodilator-stimulated phosphoprotein (VASP) at $\mathrm{Ser}^{239}$ upon reperfusion (Fig. 4). Since $\operatorname{Ser}^{239}$ of VASP is rapidly and reversibly phosphorylated when PKG is activated, this result indicates that PKG may play a role in the action of resveratrol during reperfusion.

\subsection{Translocation of GSK-3 $\beta$ to mitochondria and its interaction with cyclophilin $D$}

While GSK- $3 \beta$ phosphorylation at $\operatorname{Ser}^{9}$ is proposed to lead to inhibition of the mPTP opening, the exact mechanism underlying the action remains unknown. We hypothesized that GSK-3 $\beta$ phosphorylation by resveratrol results in translocation of GSK-3 $\beta$ to mitochondria and this translocated GSK-3 $\beta$ interacts with components of the mPTP. In agreement with our hypothesis, resveratrol translocated GSK-3 $\beta$ to mitochondrial under normoxic conditions in cardiomyocytes (Fig. 5A). Furthermore, resveratrol also significantly increased the mitochondrial GSK-3 $\beta$ content compared to the control upon reperfusion (Fig. 5B), indicating that resveratrol indeed translocates GSK-3 $\beta$ at reperfusion. Tubulin is a cytosolic protein and was not detected in the mitochondrial fraction, verifying purification of mitochondria from 
cytosolic fraction (Fig. 5A). To determine if translocated GSK-3 $\beta$ contributes to the inhibitory effect of resveratrol on the mPTP opening, we tested if GSK-3 $\beta$ interacts with components of the $\mathrm{mPTP}$. The $\mathrm{mPTP}$ is composed of VDAC (voltage dependent anion channel), ANT (adenine nucleotide translocator), and cyclophilin D (Crompton, 1999). We found that GSK-3 $\beta$ coprecipitated with cyclophilin D but not with VDAC or ANT (Fig. 6) in isolated cardiomyocytes treated with resveratrol, indicating that translocated GSK-3 $\beta$ may interact with cyclophilin D to modulate the mPTP opening.

\section{Discussion}

Resveratrol, which is present in high concentrations in red wine, has been demonstrated to protect the heart from ischemia/reperfusion injury by inducing pharmacological preconditioning when given before the onset of ischemia in various experimental preparations (Bradamante et al., 2003; Das et al., 2005a, 2006b; Hattori et al., 2002; Hung et al., 2004; Imamura et al., 2002). However, since preconditioning is seldom possible in the clinical setting of acute myocardial infarction, cardioprotective interventions applied after the onset of ischemia or at reperfusion would appear to have greater clinical potential. Thus, we examined if resveratrol applied at reperfusion could protect the heart from ischemia/reperfusion injury in rat hearts. Out data show that resveratrol administered starting 5 min prior to the onset of reperfusion significantly reduced infarct size, suggesting that resveratrol is capable of preventing reperfusion injury and thus has a great therapeutic potential in the clinical setting of acute myocardial infarction.

The mPTP opening is a critical determinant of ischemia/reperfusion injury in the heart (Suleiman et al., 2001; Weiss et al., 2003). A recent observation that the mPTP opens in the first few minutes of reperfusion but not during ischemia (Griffiths and Halestrap, 1995) suggests that there is a potential opportunity to protect the heart during the first few minutes of reperfusion by modulating the mPTP opening. In support, inhibition of the mPTP opening with sanglifehrin-A during the first few minutes of reperfusion leads to cardioprotection against infarction (Hausenloy et al., 2003). Similarly, inhibition of the mPTP opening at the onset of reoxygenation with cyclosporin-A or sanglifehrin-A protected human myocardium against lethal hypoxia/reoxygenation injury (Shanmuganathan et al., 2005). A recent finding that postconditioning protects rabbit hearts by inhibiting the MPTP opening (Argaud et al., 2005b) further supports the essential role of the MPTP in prevention of reperfusion injury. Our recent studies have also demonstrated that bradykinin (Park et al., 2006b) and IB-MECA (Park et al., 2006a) protect the heart at reperfusion by inhibiting the mPTP opening. Thus, it is possible that resveratrol protects the heart at reperfusion by targeting the mPTP. In this study, we found that resveratrol prevented mitochondrial swelling, confirming the critical role of the $\mathrm{mPTP}$ in the action of resveratrol. Thus, our data support the prevalent notion that the mPTP is a common target for various cardioprotective interventions at reperfusion (Di Lisa and Bernardi, 2006).

GSK-3 $\beta$ activity is regulated by phosphorylation at its $\operatorname{Ser}^{9}$ and $\operatorname{Tyr}^{216}$. Phosphorylation of Ser $^{9}$ decreases GSK-3 $\beta$ activity, whereas phosphorylation of Tyr $^{216}$ increases GSK-3 $\beta$ activity (Gross et al., 2004). GSK-3 $\beta$ is constitutively activated due to basal phosphorylation of $\mathrm{Tyr}^{216}$. GSK-3 $\beta$ inactivation by pharmacological preconditioning has been proposed to modulate the mPTP opening in cardiomyocytes (Juhaszova et al., 2004), and opioids protect the heart at reperfusion by inhibiting GSK-3 $\beta$ in rats (Gross et al., 2004). Bradykinin and the adenosine $\mathrm{A}_{3}$ receptor agonist IB-MECA applied at reperfusion protected hearts by modulating the mPTP through GSK-3 $\beta$ inhibition (Park et al., 2006a,b). In this study, resveratrol enhanced GSK-3 $\beta$ phosphorylation at $\operatorname{Ser}^{9}$ upon reperfusion, implying that GSK-3 $\beta$ may play a role in the action of resveratrol. Although it is now known that GSK-3 $\beta$ inactivation leads to inhibition of the mPTP opening, it remains unclear how the cytosol signal modulates the mitochondrial 
function. We hypothesized that resveratrol induces translocation of GSK-3 $\beta$ to mitochondria where GSK-3 $\beta$ interacts with the mPTP. In this study, GSK-3 $\beta$ is translocated to mitochondria by resveratrol and is thus optimally positioned for modulation of the MPTP opening at reperfusion. In a previous study (Bijur and Jope, 2003), Bijur and Jope reported that phosphoGSK-3 $\beta$ at $\operatorname{Ser}^{9}$ was nearly undetectable in brain mitochondria and that mitochondria GSK- $3 \beta$ is in a very active state, due in part to the low level of inhibition by phosphorylation at Ser9. We found that the level of total GSK-3 $\beta$ in mitochondria was negligible under physiological conditions when compared to that in cytosol. Thus, the sizable amount of GSK- $3 \beta$ translocated by resveratrol from cytosol could increase the level of the inactivated form in the mitochondrial pool of GSK-3 $\beta$, because the GSK-3 $\beta$ activity is much lower in cytosol than in mitochondria under physiological conditions (Bijur and Jope, 2003). Since the inhibitors of GSK-3 $\beta$ and the catalytically inactive mutant of GSK-3 $\beta$ are protective against ischemia/reperfusion injury (Gross et al., 2004; Yin et al., 2005), the increase in the inactivated form of GSK-3 $\beta$ in mitochondria may account for the action of resveratrol. However, it should be mentioned that although inactivation of GSK-3 $\beta$ leads to cardioprotection, little is known about the relationship between the kinase activity and the mPTP opening.

NO has been proposed to contribute to the mechanism underlying resveratrol-induced cardioprotection (Bradamante et al., 2003; Hattori et al., 2002) and the NO/cGMP/PKG signaling pathway has been documented to be involved in the mechanism of cardioprotection (Krieg et al., 2002; Oldenburg et al., 2003). In this study, resveratrol-induced GSK-3 $\beta$ phosphorylation and translocation were prevented by the guanylyl cyclase inhibitor ODQ, and resveratrol could increase VASP phosphorylation at reperfusion, indicating that the cGMP/ PKG pathway is involved in the action of resveratrol. Moreover, the observation that both phosphorylation and translocation of GSK- $3 \beta$ were blocked by ODQ may imply that these two

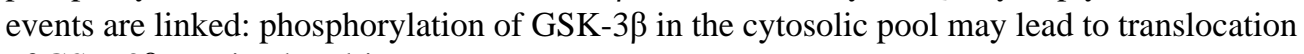
of GSK-3 $\beta$ to mitochondria.

Although a number of cardioprotective interventions have been reported to inhibit the mPTP opening, it is still unclear how cytosolic signaling events initiated by the interventions interact with the components of the mPTP. Since GSK-3 $\beta$ is optimally positioned (through translocation to mitochondria by resveratrol) for interaction with the mPTP components, we sought to identify which component (s) of the mPTP contribute (s) to the protective action of resveratrol by interacting with translocated GSK-3 $\beta$. Our data show that GSK-3 $\beta$ interacts with cyclophilin D but not with VDAC or ANT, suggesting that cyclophilin D but not VDAC or ANT is critical for the inhibitory effect of resveratrol on the mPTP opening. This result supports the previous observations by others that cyclophilin D plays a critical role in the mPTP opening and cell death (Baines et al., 2005; Lim et al., 2007). Our finding may also support the recent reports that threw doubt on the roles of ANT (Kokoszka et al., 2004) and VDAC (Baines et al., 2007) in the pore opening. However, recently Nishihara et al. reported that ischemic preconditioning plus erythropoietin protected the heart by increasing phospho-GSK-3 $\beta$ binding to ANT, suggesting that ANT plays an important role in the cardioprotective effect of ischemic preconditioning plus erythropoietin (Nishihara et al., 2007). The authors proposed that physical interaction of phospho-GSK-3 $\beta$ with ANT increases the threshold of the mPTP opening by reducing ANT affinity to cyclophilin D. Nevertheless, more studies are needed to define the exact role of ANT in the mPTP opening, since mitochondria lacking ANT genes could still be induced to undergo permeability transition (Kokoszka et al., 2004).

In conclusion, resveratrol protects the heart at reperfusion presumably by modulating the $\mathrm{mPTP}$ opening in a GSK-3 $\beta$-dependent manner. Resveratrol inactivates GSK- $3 \beta$ and induces GSK-3 $\beta$ translocation to mitochondria through the cGMP/PKG signaling pathway. Translocated GSK- $3 \beta$ may modulate the mPTP opening by interacting with cyclophilin D. 


\section{Acknowledgments}

This work was partially supported by the National Institute of Health Grant R01HL08336.

\section{References}

Argaud L, Gateau-Roesch O, Muntean D, Chalabreysse L, Loufouat J, Robert D, Ovize M. Specific inhibition of the mitochondrial permeability transition prevents lethal reperfusion injury. J. Mol. Cell. Cardiol 2005a;38:367-374. [PubMed: 15698843]

Argaud L, Gateau-Roesch O, Raisky O, Loufouat J, Robert D, Ovize M. Postconditioning inhibits mitochondrial permeability transition. Circulation 2005b;111:194-197. [PubMed: 15642769]

Baines CP, Zhang J, Wang GW, Zheng YT, Xiu JX, Cardwell EM, Bolli R, Ping P. Mitochondrial PKCepsilon and MAPK form signaling modules in the murine heart: enhanced mitochondrial PKCepsilon-MAPK interactions and differential MAPK activation in PKCepsilon-induced cardioprotection. Circ. Res 2002;90:390-397. [PubMed: 11884367]

Baines CP, Kaiser RA, Purcell NH, Blair NS, Osinska H, Hambleton MA, Brunskill EW, Sayen MR, Gottlieb RA, Dorn GW, Robbins J, Molkentin JD. Loss of cyclophilin D reveals a critical role for mitochondrial permeability transition in cell death. Nature 2005;434:658-662. [PubMed: 15800627]

Baines CP, Kaiser RA, Sheiko T, Craigen WJ, Molkentin JD. Voltage-dependent anion channels are dispensable for mitochondrial-dependent cell death. Nat. Cell Biol 2007;9:550-555. [PubMed: 17417626]

Bijur GN, Jope RS. Glycogen synthase kinase-3b is highly activated in nuclei and mitochondria. NeuroReport 2003;14:2415-2419. [PubMed: 14663202]

Birrell MA, McCluskie K, Wong S, Donnelly LE, Barnes PJ, Belvisi MG. Resveratrol, an extract of red wine, inhibits lipopolysaccharide induced airway neutrophilia and inflammatory mediators through an NF-kappaB-independent mechanism. FASEB J 2005;19:840-841. [PubMed: 15734790]

Bradamante S, Barenghi L, Piccinini F, Bertelli AAE, De Jonge R, Beemster P, De Jong JW. Resveratrol provides late-phase cardioprotection by means of a nitric oxide- and adenosine-mediated mechanism. Eur. J. Pharmacol 2003;465:115-123. [PubMed: 12650840]

Braunwald E, Kloner RA. Myocardial reperfusion: a double-edged sword? J. Clin. Invest 1985;76:17131719. [PubMed: 4056048]

Crompton M. The mitochondrial permeability transition pore and its role in cell death. Biochem. J 1999;341:233-249. [PubMed: 10393078]

Das S, Cordis GA, Maulik N, Das DK. Pharmacological preconditioning with resveratrol: role of CREBdependent Bcl-2 signaling via adenosine A3 receptor activation. Am. J. Physiol 2005a;288:H328$\mathrm{H} 335$.

Das S, Tosaki A, Bagchi D, Maulik N, Das DK. Resveratrol-mediated activation of cAMP response element-binding protein through adenosine A3 receptor by Akt-dependent and -independent pathways. J. Pharmacol. Exp. Ther 2005b;314:762-769. [PubMed: 15879002]

Das S, Fraga CG, Das DK. Cardioprotective effect of resveratrol via HO-1 expression involves p38 map kinase and PI-3-kinase signaling, but does not involve NFkappaB. Free Radic. Res 2006a;40:10661075. [PubMed: 17015251]

Das S, Tosaki A, Bagchi D, Maulik N, Das DK. Potentiation of a survival signal in the ischemic heart by resveratrol through $\mathrm{p} 38$ mitogen-activated protein kinase/mitogen- and stress-activated protein kinase 1/cAMP response element-binding protein signaling. J. Pharmacol. Exp. Ther 2006b; 317:980-988. [PubMed: 16525036]

Di Lisa F, Bernardi P. Mitochondria and ischemia-reperfusion injury of the heart: fixing a hole. Cardiovasc. Res 2006;70:191-199. [PubMed: 16497286]

Frame S, Cohen P. GSK3 takes centre stage more than 20 years after its discovery. Biochem. J 2001;359:1-16. [PubMed: 11563964]

Frankel EN, Waterhouse AL, Kinsella JE. Inhibition of human LDL oxidation by resveratrol. Lancet 1993;341:1103-1104. [PubMed: 8097009]

Griffiths EJ, Halestrap AP. Mitochondrial non-specific pores remain closed during cardiac ischaemia, but open upon reperfusion. Biochem. J 1995;307:93-98. [PubMed: 7717999] 
Gross ER, Hsu AK, Gross GJ. Opioid-induced cardioprotection occurs via glycogen synthase kinase b inhibition during reperfusion in intact rat hearts. Circ. Res 2004;94:960-966. [PubMed: 14976126]

Hadzimichalis NM, Baliga SS, Golfetti R, Jaques KM, Firestein BL, Merrill GF. Acetaminophenmediated cardioprotection via inhibition of the mitochondrial permeability transition pore-induced apoptotic pathway. Am. J. Physiol 2007;293:H3348-H3355.

Halestrap AP, Clarke SJ, Javadov SA. Mitochondrial permeability transition pore opening during myocardial reperfusion—a target for cardioprotection. Cardiovasc. Res 2004;61:372-385. [PubMed: 14962470]

Hattori R, Otani H, Maulik N, Das DK. Pharmacological preconditioning with resveratrol: role of nitric oxide. Am. J. Physiol 2002;282:H1988-H1995.

Hausenloy DJ, Maddock HL, Baxter GF, Yellon DM. Inhibiting mitochondrial permeability transition pore opening: a new paradigm for myocardial preconditioning? Cardiovasc. Res 2002;55:534-543. [PubMed: 12160950]

Hausenloy DJ, Duchen MR, Yellon DM. Inhibiting mitochondrial permeability transition pore opening at reperfusion protects against ischaemia-reperfusion injury. Cardiovasc. Res 2003;60:617-625. [PubMed: 14659807]

Hung L-M, Su M-J, Chen J-K. Resveratrol protects myocardial ischemia- reperfusion injury through both NO-dependent and NO-independent mechanisms. Free Radic. Biol. Med 2004;36:774-781. [PubMed: 14990356]

Imamura G, Bertelli AA, Bertelli A, Otani H, Maulik N, Das DK. Pharmacological preconditioning with resveratrol: an insight with iNOS knockout mice. Am. J. Physiol 2002;282:H1996-H2003.

Jang M, Cai L, Udeani GO, Slowing KV, Thomas CF, Beecher CWW, Fong HHS, Farnsworth NR, Kinghorn AD, Mehta RG, Moon RC, Pezzuto JM. Cancer chemopreventive activity of resveratrol, a natural product derived from grapes. Science 1997;275:218-220. [PubMed: 8985016]

Juhaszova M, Zorov DB, Kim SH, Pepe S, Fu Q, Fishbein KW, Ziman BD, Wang S, Ytrehus K, Antos CL, Olson EN, Sollott SJ. Glycogen synthase kinase-3b mediates convergence of protection signaling to inhibit the mitochondrial permeability transition pore. J. Clin. Invest 2004;113:1535-1549. [PubMed: 15173880]

Kokoszka JE, Waymire KG, Levy SE, Sligh JE, Cai J, Jones DP, MacGregor GR, Wallace DC. The ADP/ ATP translocator is not essential for the mitochondrial permeability transition pore. Nature 2004;427:461-465. [PubMed: 14749836]

Krieg T, Qin Q, McIntosh EC, Cohen MV, J.M. D. ACh and adenosine activate PI3-kinase in rabbit hearts through transactivation of receptor tyrosine kinases. Am. J. Physiol., Heart Circ. Physiol 2002;283:H2322-H2330. [PubMed: 12388234]

Lim SY, Davidson SM, Hausenloy DJ, Yellon DM. Preconditioning and postconditioning: the essential role of the mitochondrial permeability transition pore. Cardiovasc. Res 2007;75:530-535. [PubMed: 17512507]

Nishihara M, Miura T, Miki T, Tanno M, Yano T, Naitoh K, Ohori K, Hotta H, Terashima Y, Shimamoto K. Modulation of the mitochondrial permeability transition pore complex in GSK-3b-mediated myocardial protection. J. Mol. Cell. Cardiol 2007;43:564-570. [PubMed: 17931653]

Oldenburg O, Qin Q, Krieg T, Yang XM, Philipp S, Critz SD, Cohen MV, Downey JM. Bradykinin induces mitochondrial ROS generation via NO, cGMP, PKG, and mKATP channel opening and leads to cardioprotection. Am. J. Physiol., Heart Circ. Physiol 2003;286:H468-H476. [PubMed: 12958031]

Park S-S, Zhao H, Jang Y, Mueller RA, Xu Z. N6-(3-Iodobenzyl)-adenosine-5'-N-methylcarboxamide confers cardioprotection at reperfusion by inhibiting mitochondrial permeability transition pore opening via glycogen synthase kinase 3b. J. Pharmacol. Exp. Ther 2006a;318:124-131. [PubMed: 16611852]

Park SS, Zhao H, Mueller R, Xu Z. Bradykinin prevents reperfusion injury by targeting mitochondrial permeability transition pore through glycogen synthase kinase 3b. J. Mol. Cell. Cardiol 2006b; 40:708-716. [PubMed: 16516918]

Shanmuganathan S, Hausenloy DJ, Duchen MR, Yellon DM. Mitochondrial permeability transition pore as a target for cardioprotection in the human heart. Am. J. Physiol 2005;289:H237-H242. 
Suleiman M-S, Halestrap AP, Griffiths EJ. Mitochondria: a target for myocardial protection. Pharmacol. Ther 2001;89:29-46. [PubMed: 11316512]

Tong H, Imahashi K, Steenbergen C, Murphy E. Phosphorylation of glycogen synthase kinase-3b during preconditioning through a phosphatidylinositol-3-kinase-dependent pathway is cardioprotective. Circ. Res 2002;90:377-379. [PubMed: 11884365]

Wang G, Liem DA, Vondriska TM, Honda HM, Korge P, Pantaleon DM, Qiao X, Wang Y, Weiss JN, Ping P. Nitric oxide donors protect the murine myocardium against infarction via modulation of mitochondrial permeability transition. Am. J. Physiol 2005;288:H1290-H1295.

Weiss JN, Korge P, Honda HM, Ping P. Role of the mitochondrial permeability transition in myocardial disease. Circ. Res 2003;93:292-301. [PubMed: 12933700]

Wood JG, Rogina B, Lavu S, Howitz K, Helfand SL, Tatar M, Sinclair D. Sirtuin activators mimic caloric restriction and delay ageing in metazoans. Nature 2004;430:686-689. [PubMed: 15254550]

Xu Z, Park SS, Mueller RA, Bagnell RC, Patterson C, Boysen PG. Adenosine produces nitric oxide and prevents mitochondrial oxidant damage in rat cardiomyocytes. Cardiovasc. Res 2005;65:803-812. [PubMed: 15721860]

Yin H, Chao L, Chao J. Kallikrein/kinin protects against myocardial apoptosis after ischemia/reperfusion via Akt-glycogen synthase kinase-3 and Akt-Bad14-3-3 signaling pathways. J. Biol. Chem 2005;280:8022-8030. [PubMed: 15611141] 

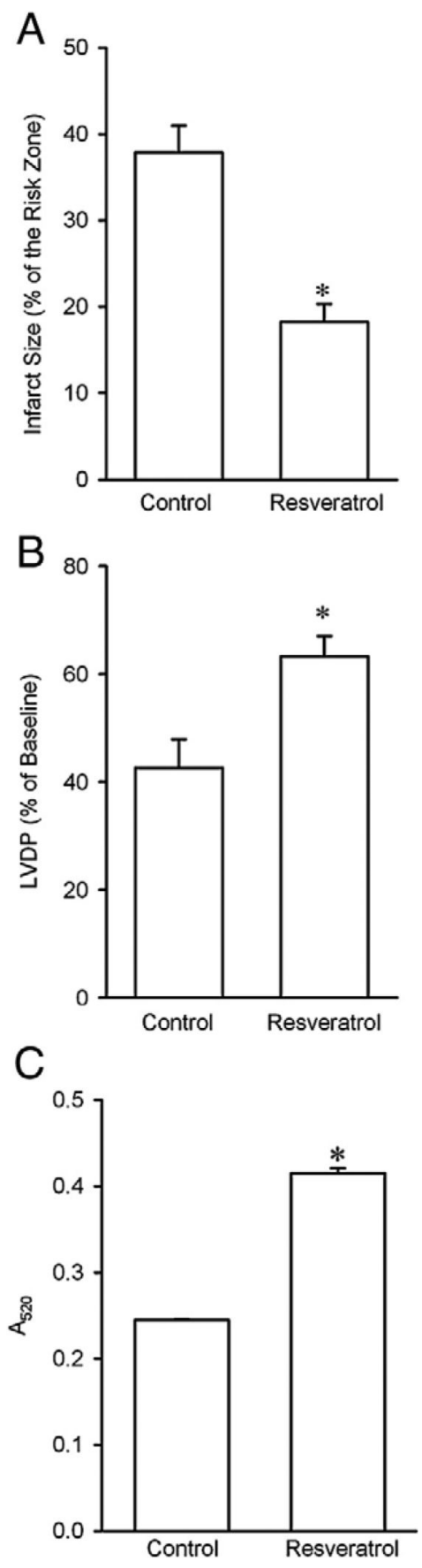

Fig. 1.

A, Effect of resveratrol on myocardial infarct size in isolated rat hearts subjected to 30 min of regional ischemia followed by $2 \mathrm{~h}$ of reperfusion. Resveratrol $(10 \mu \mathrm{M}, n=8)$ significantly reduced infarct size compared to the control $(n=8)$. *, $P<0.05$ versus control ( $t$-test). B, Effect of resveratrol $(10 \mu \mathrm{M})$ on cardiac contractile function at reperfusion. Resveratrol increased left ventricular developed pressure (LVDP) at $2 \mathrm{~h}$ of reperfusion. ${ }^{*}, P<0.05$ versus control ( $t$-test, $n=8$ each group). $\mathrm{C}$, Resveratrol $(10 \mu \mathrm{M}, n=13)$ prevented mitochondrial swelling at reperfusion (control, $n=13$ ). Mitochondrial swelling was measured as a decrease in absorbance at $520 \mathrm{~nm}\left(A_{520}\right) .{ }^{*}, P<0.05$ versus control $(t$-test $)$. 

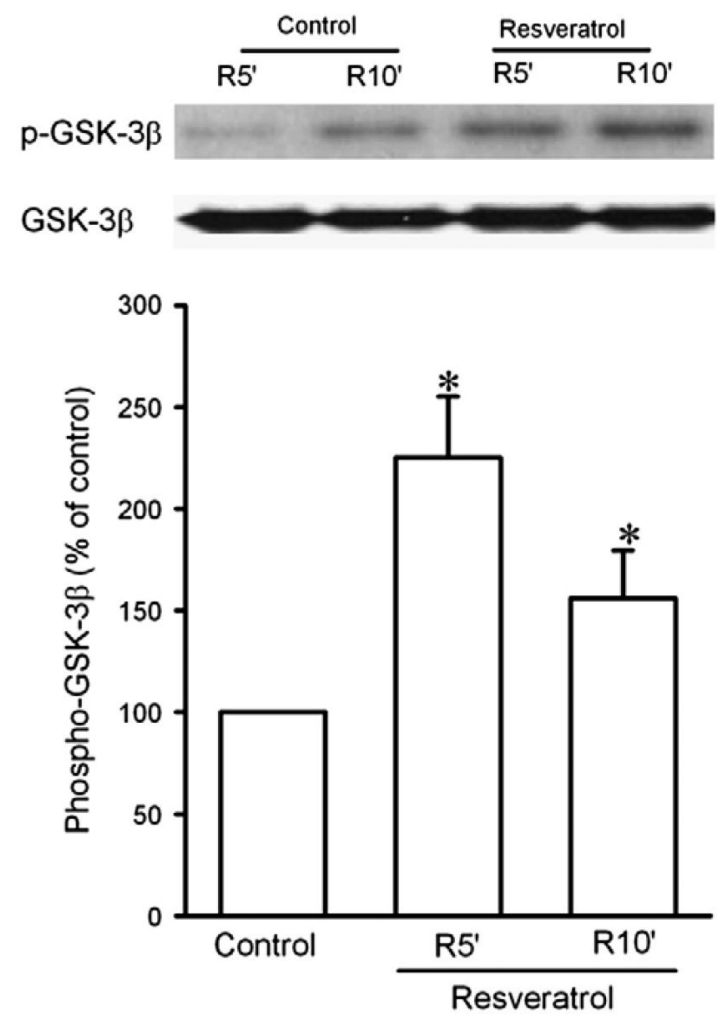

Fig. 2.

Western blotting analysis of phospho-GSK-3 $\beta$ at $\operatorname{Ser}^{9}$ and total GSK-3 $\beta$ protein in isolated rat hearts. Myocardial samples were collected from the risk zone at 5 (R5') and 10 (R10') min after the onset of reperfusion. Resveratrol $(10 \mu \mathrm{M}, n=6)$ significantly enhanced GSK-3 $\beta$ phosphorylation at reperfusion compared to control $(n=6)$. ${ }^{*}, P<0.05$ versus control ( $t$-test). 

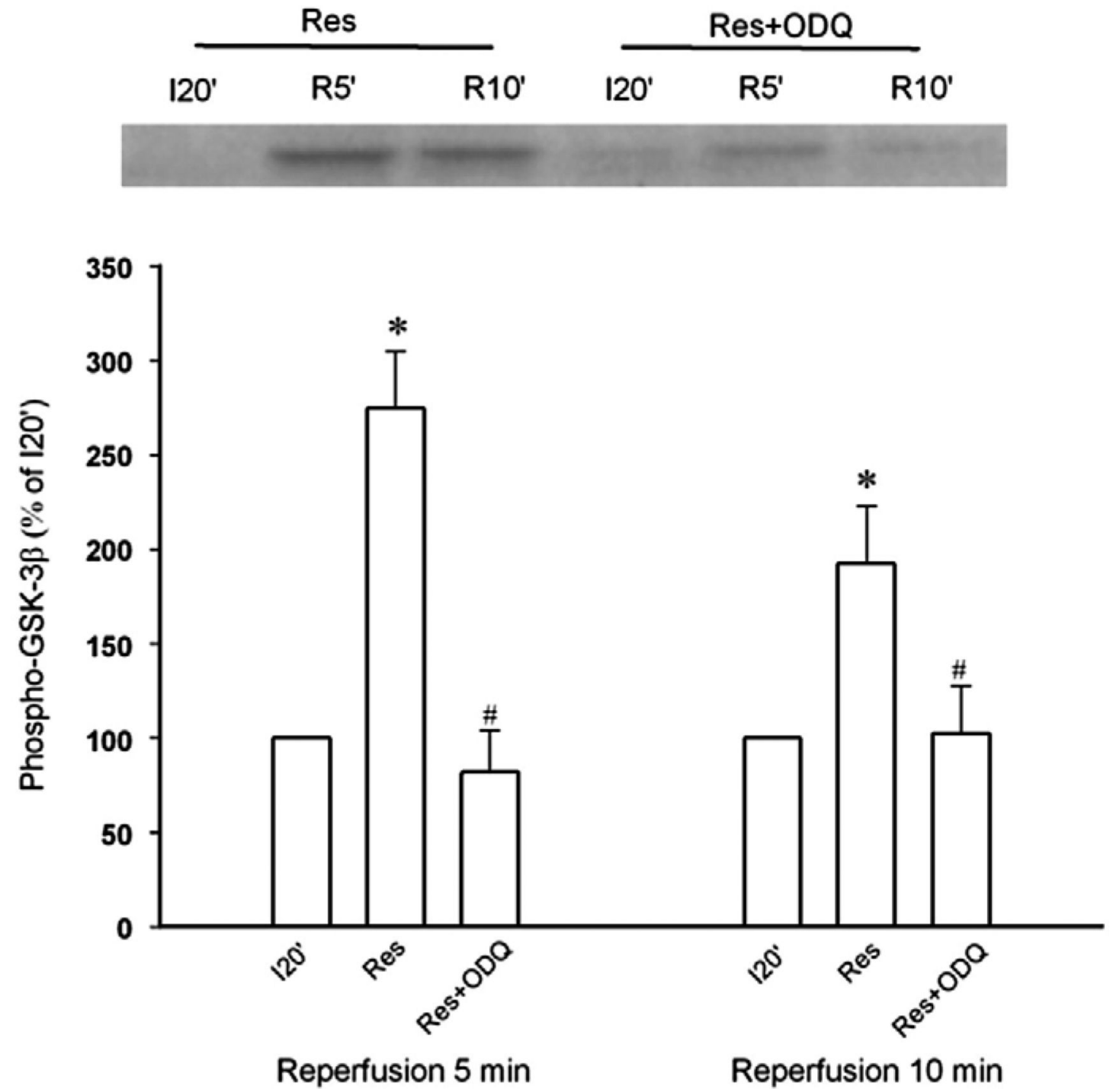

Fig. 3.

Western blotting analysis of phospho-GSK-3 $\beta$ at Ser $^{9}$ in isolated rat hearts. Myocardial samples were collected from the risk zone at $20 \mathrm{~min}$ after the onset of ischemia (I20'), 5 (R5') and $10\left(\mathrm{R} 10^{\prime}\right)$ min after the onset of reperfusion. Resveratrol (Res, $\left.10 \mu \mathrm{M}, n=6\right)$-induced GSK-3 $\beta$ phosphorylation at reperfusion was reversed by the guanylyl cyclase inhibitor ODQ $(5 \mu \mathrm{M}, n=7)$. *,$P<0.05$ versus I20';,$P<0.05$ versus resveratrol (Res); ANOVA followed by Tukey's test. 


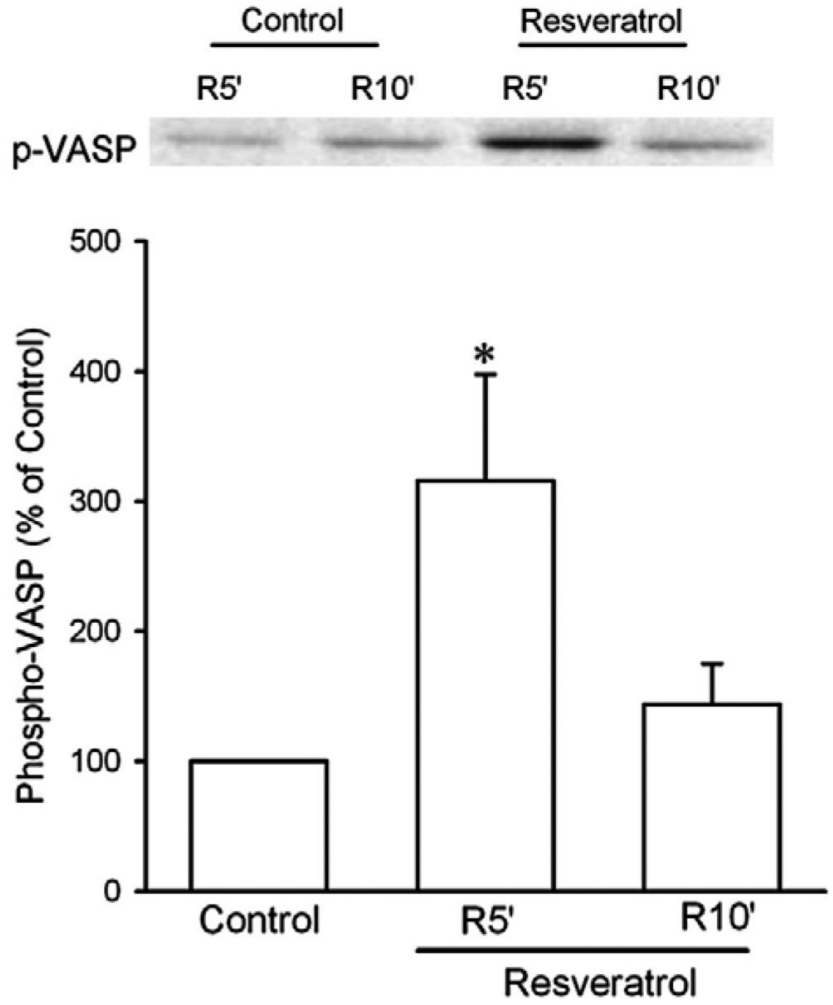

Fig. 4.

Western blotting analysis of phospho-VASP in isolated rat hearts. Myocardial samples were collected from the risk zone at $5\left(\mathrm{R}^{\prime}\right)$ and $10\left(\mathrm{R} 10^{\prime}\right)$ min after the onset of reperfusion.

Resveratrol $(10 \mu \mathrm{M})$ significantly enhanced VASP phosphorylation at reperfusion. *, $P<0.05$ versus control ( $t$-test, $n=6$ each group). 

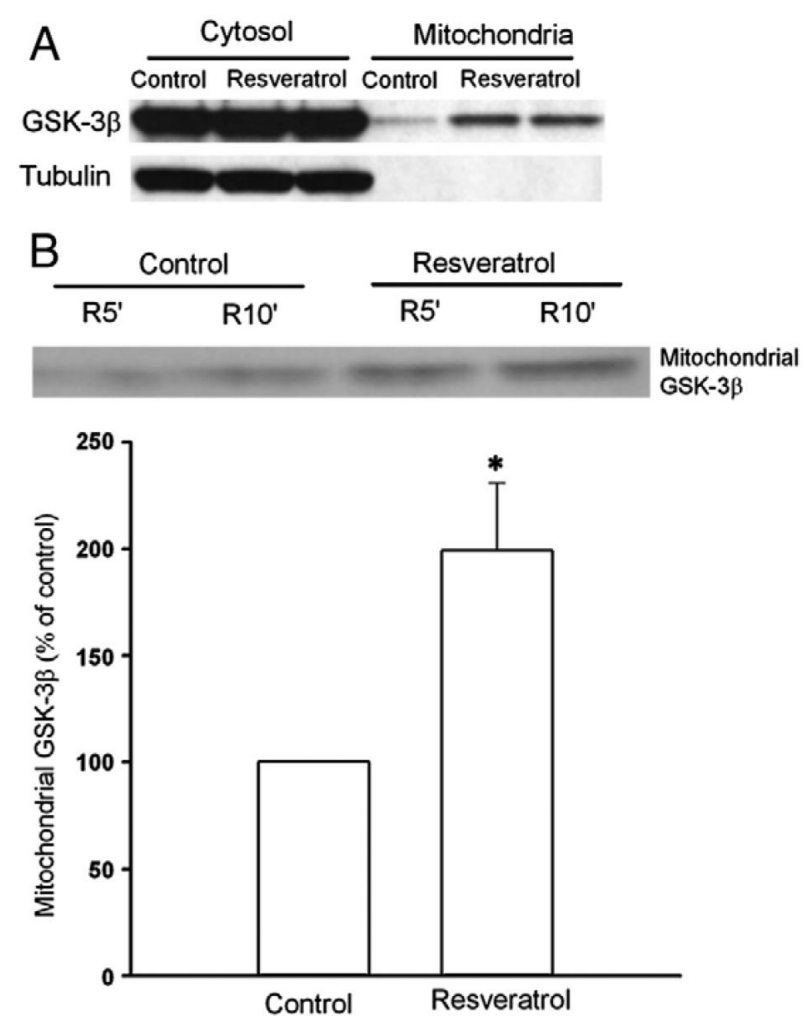

Fig. 5.

Western blotting analysis of cytosolic and mitochondrial GSK-3 $\beta$ protein. A, Resveratrol (10 $\mu \mathrm{M}, 10 \mathrm{~min}$ ) increases GSK-3 $\beta$ in mitochondria under normoxic conditions in cardiomyocytes. $\mathrm{B}$, Mitochondria were isolated from isolated rat hearts $5\left(\mathrm{R}^{\prime}\right)$ and $10\left(\mathrm{R} 10^{\prime}\right)$ min after the onset of reperfusion. Resveratrol $(10 \mu \mathrm{M})$ induced GSK- $3 \beta$ translocation to mitochondria upon reperfusion. *, $P<0.05$ versus control ( $t$-test, $n=8$ each group). 


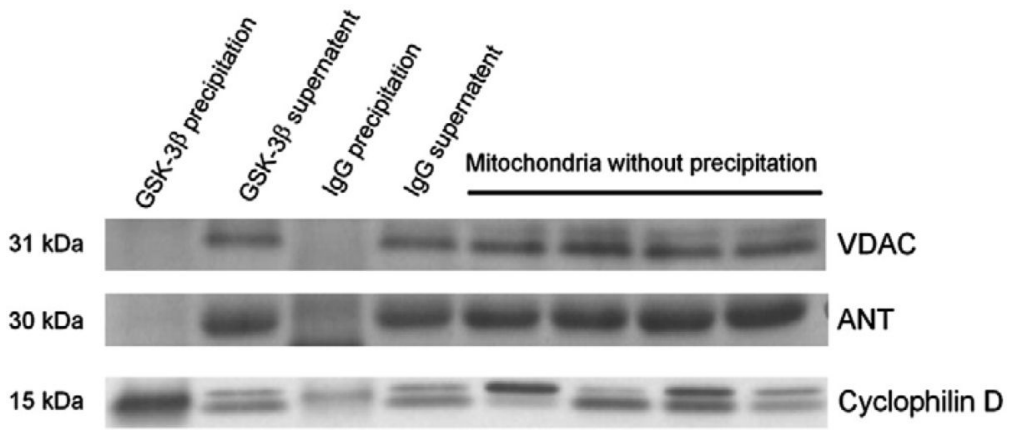

Fig. 6.

Mitochondria isolated from adult rat cardiomyocytes treated with resveratrol $(10 \mu \mathrm{M}, 10 \mathrm{~min})$ were immunoprecipitated for GSK-3 $\beta$ and IgG (rabbit). The precipitates, the supernatants, and the mitochondria proteins that did not undergo immunoprecipitation were immunoblotted using anti-VDAC and anti-ANT, and anti-cyclophilin D antibodies. Rabbit IgG was used as control immunoprecipitation. GSK-3 $\beta$ was coprecipitated with cyclophilin D but not with VDAC or ANT. 